\title{
THE NATURE OF MENTAL DEFICIENCY.
}

\author{
By LEONARD FINDLAY, M.D., D.Sc. \\ (Physician, Princess Elizabeth of York Hospital for Children.)
}

During the last decade interest in the cause and prevention of mental deficiency has steadily and rapidly increased. The culmination of this interest was reached last year with the appearance of the Report of the Departmental Committee on Sterilization, ${ }^{(1)}$ which purports to outline the best means for the eradication of this blemish on our civilization. Before, however, there can be promulgated any satisfactory prophylactic or remedial measures it is necessary that the nature of the problem be fully understood as well as the cause or causes of the condition discovered. Unfortunately, so far as the nature of mental deficiency is concerned there prevails the greatest confusion of thought, and regarding the cause it can, I think, be truthfully stated that we are for the most part still in complete ignorance. In the present paper I intend to limit my attention almost entirely to the former question-the nature of mental deficiency-because without a proper appreciation of this fundamental point absolutely wrong methods of study in a search after the probable cause might be, as they indeed have been, adopted.

The introduction of the measurement of intelligence (i.e., the determination of the mental ratio') is one of the real advances within our time in the study of mental deficiency. By this means we are now able not only to recognise its presence with a definiteness that was previously impossible, but we are also permitted to estimate the degree of the mental retardation. At the same time, however, it has unfortunately led to some very wrong conceptions. It is, for instance, chiefly responsible for the modern tendency to consider the mental state as the only factor in the question. Since the mental retardation is without doubt the most serious element in the case, both from the medical and sociological aspects, there is perhaps some excuse for this point of view, but it is an attitude which can produce nothing but confusion because it brings about a grouping together of types of mental deficiency which have very different underlying causes and fundamentally have absolutely nothing in common.

\section{Normal Variation in Intelligence.}

There is no doubt that intelligence, i.e., the natural mental capacity of the individual, is not a constant feature in any community. Like other characteristics, it is subject to a wide range of variation. By submitting a large group of individuals to the so-called intelligence tests, which give an exact numerical expression to the degree of mental development just as the foot-rule does for height and the scales for weight, it can be shown that the degree of variation above and below the mean diminishes with almost equal and gradually lessening frequency. 
The distribution of the varying degrees of intelligence can be represented graphically and this I have done for three different groups of children in the following diagram (Chart I). One of the curves refers to the investigation conducted by Terman ${ }^{(2)}$ of 905 unselected American school children. The other two

CHART I.

Graphic representation of percentage incidence of various degrees of mental intelligence in three groups of children.

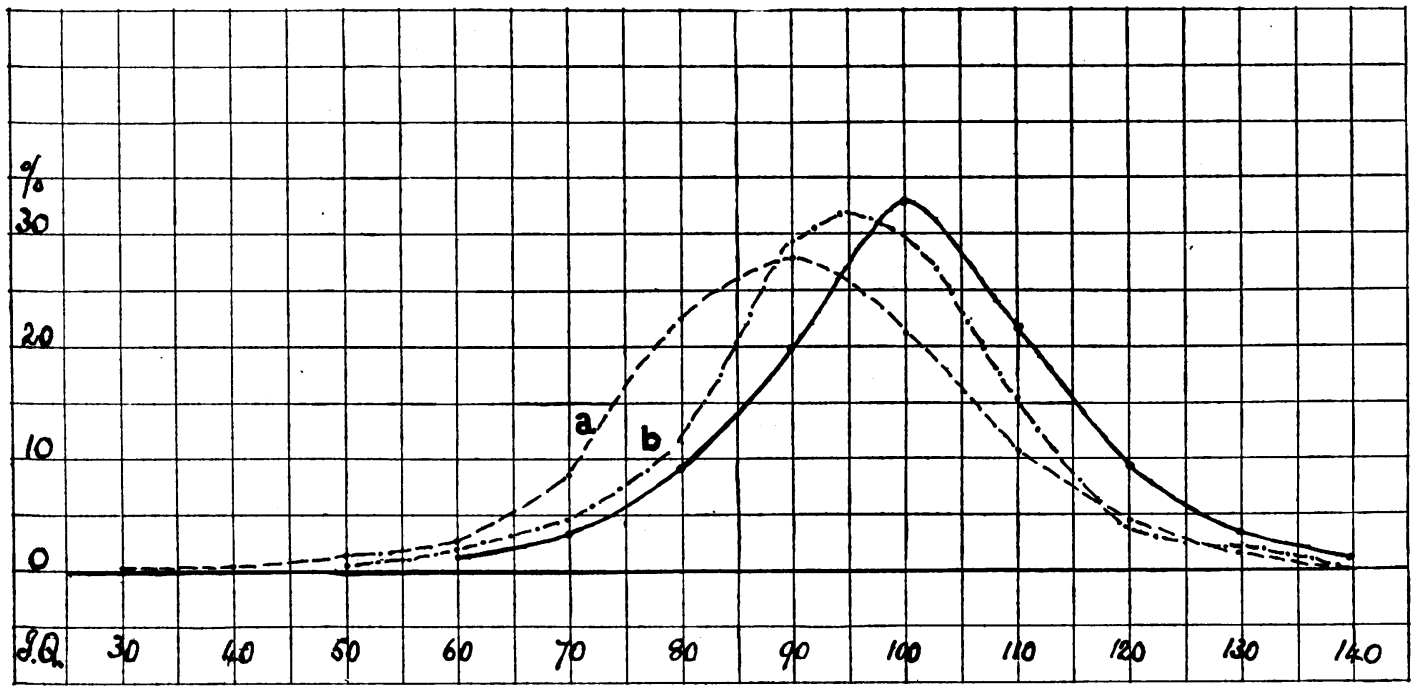

- - - Dawson (1020 inmates Royal Hospital for Sick Children, Glasgow).

— - - - Dawson (250 scarlet fever patients, Ruchill Isolation Hospital, Glasgow).

curves are constructed from the findings of Dr. Shepherd Dawson ${ }^{(3)}$ in the case of Glasgow children, (a) the inmates of the medical wards of the Royal Hospital for Sick Children but excluding all examples of mental deficiency, and (b), the scarletfever patients in Ruchill Isolation Hospital.

The general trend of the three curves is the same, a fairly rapid fall on either side of the mean which, however, tails off and becomes almost horizontal as the highest and lowest limits are reached. The American curve shows a slightly higher mean which may be accounted for by a difference in the tests applied rather than by a superiority of intelligence. In the case of the Glasgow children the same tests were employed throughout. The flatness of the curve (a) referring to the Royal Hospital for Sick Children group, with the relatively increased number of lower readings, is to be accounted for by the fact that the patients in this hospital are for the most part recruited from the poorest classes of society. If the mentally defective children admitted to the wards had been included, there would undoubtedly have resulted an even lower mean, and also a probable heaping of the curve at the extreme lower end, but this was not done because it was appreciated that such an inclusion would have rendered the findings of little value for comparison with the general population. Since practically all the subjects of Scarlet Fever 
in Glasgow are admitted to hospital, the curve $(b)$ gives a truer estimate of the intelligence of the general population in that City and, on the whole, it closely approximates to that of the 905 unselected American children studied by Terman. Burt ${ }^{(4)}$ has published a curve for London School Children which shows the same behaviour: this curve was constructed from the study of children in elementary and special schools after correction had been made for the relative proportion of these two types of scholars.

\section{Inheritance of Intelligence.}

There would also seem good reason to believe that intelligence is hereditary just as much as other bodily characteristics. Parents of high intelligence are, on the average, more likely than those of lower intelligence to have children of high intelligence, just as tall parents are more likely than small parents to have tall progeny. In the words of the Departmental Committee on Sterilization, "Highly gifted parents tend to have highly gifted children and dull parents tend to have dull children." And in support of this view it may be noted that Terman ${ }^{(\theta)}$ found in his investigation of 999 gifted children that "The number of highly successful, even eminent, relatives" was "impressively great."

If we admit then that intelligence is hereditary and that it has the distribution shown in the appended curves, there would at first sight seem considerable justification for not drawing a hard and fast line between high and low intelligence, i.e., between the supernormal, the normal and the subnormal, and for concluding that the problem of mental deficiency is one of inheritance with the natural corollary that its prevention is a matter of the selection of the parents. This is exactly the view adopted by the Departmental Committee on Sterilization, and it is the one which at the present moment would seem to receive most support. But is it justifiable to assume that all the varying degrees of intelligence are examples of natural or physiological variation? It may be true so far as the great mass of the population are concerned including those with an intelligence of at least 70 per cent. of the mean, i.e., the high grade mental defective. Nevertheless, even among these latter, there must be, as pointed out by Lewis, ${ }^{(6)}$ many instances which are not of this nature. Slighter degrees of mental deficiency due to epilepsy, encephalitis lethargica and endocrine disturbance, for instance, cannot be considered examples of normal or physiological variation. These instances of mental deficiency are due to a pathological and hence an accidental cause. But because they compose such a relatively small proportion of the total the general trend of the curve is not disturbed and their inclusion or exclusion would not materially influence any conclusions to be drawn.

\section{Low-grade Mental Deficiency.}

Although in the case of the high grade defective the matter is, as just noted, in the vast majority of instances simply one of deficient intelligence, in the case of the low grade defective it is equally certain that it is not so. The extreme flattening of the curve in the region of the lowest readings (under 60 per cent. of the mean) would itself raise doubts regarding the lowered intelligence being 
entirely due to normal variation. Low grade mental deficiency is most certainly not a distinct and uniform pathological process. It is a heterogeneous mixture of many different conditions and the loss or arrest of intelligence is not infrequently of a concomitant or secondary nature. Indeed, it is only in something like 30 per cent. of the examples of low grade mental deficiency that subnormal intelligence is the sole abnormality to be observed. In the majority of instances there are other than mental symptoms present. In a certain proportion of the cases there are motor as well as mental symptoms, e.g., paralysis of one or more limbs, and in many of these there is a history of a difficult birth and symptoms during the first few days of life suggesting some injury of the brain. In other cases there is evidence that even the brain is not alone affected. This is particularly true of mongolian idiocy, where the whole body in common with the brain is the seat of abnormalities from defective development, and similarly, in cretinism the brain only suffers along with the body generally in consequence of deficient action of the thyroid gland. In these circumstances there certainly can be no question of the lessened intelligence being an expression of normal variation. Nor can we consider as belonging to this latter category the cases due to syphilis, or for that matter, any other infective process, such as epidemic encephalitis which within recent years has increased considerably the number of low grade mental defective children.

Hence, in a search for the cause it would seem futile to group in any analysis all examples of mental deficiency. To our mind it would seem just as reasonable to conclude that all patients with a rise in the bodily temperature above the average were suffering from the same disease as to entertain the view that all individuals with an intelligence below the average owed this to one and the same cause. Yet this seems to have been the attitude of the Departmental Committee on Sterilization when, in a search for evidence of the hereditary transmission of mental deficiency, they issued instructions to the various local authorities to include among the defective all children who were two or more years retarded educationally. By this grouping high grade and low grade mental deficiency were considered together. Now, as the high grade mental defective is in the majority, forming as he does a large proportion of the population, and, as he is admittedly as a rule an example of the hereditary transmission of intelligence, naturally a definite hereditary tendency was revealed. It would seem undoubted that the very varying estimates of heredity as a factor in the production of mental deficiency obtained by different observers is due to the varying proportions of high grade and low grade types composing the material analysed. These estimates from foreign sources, as quoted by the Departmental Committee on Sterilization, range from 6.6 to 56 per cent.

No! if we are to arrive at the truth in this matter it will only be reached by studying apart the high grade and the low grade defective and the various definite types of which this latter group is composed. The various clinical pictures must be taken into consideration. To such a system of analysis there is no valid objection so long as sufficiently large numbers of examples of each type are available for study. Indeed, it might be expected $a$ priori that the ætiological factor, whatever it is, would be most evident in the most severe examples of the condition, i.e., the low grade mental defective. 
Such a study I have recently made of all the examples of congenital low grade mental deficiency which I have observed in private practice in the West of Scotland during the course of 20 years. ${ }^{(7)}$ Perhaps the most striking fact which emerged from the analysis of this material was the agreement of the findings relative to the proportion of the various types of the condition with those obtained by the late Dr. John Thomson ${ }^{(8)}$ for children resident in the East of Scotland. Roughly, 30 per cent were aments, 30 per cent were mongols, and 30 per cent were suffering from spastic diplegia or hemiplegia. So far as the influence of heredity was concerned this did not seem to be a factor of great significance. In no variety of congenital low grade mental deficiency was there a history in the patients' forebears or relatives of a condition of the same nature in more than 6.6 per cent, excepting in the case of spastic hemiplegia. In this variety of the malady with a definite history of birth injury a positive family history was obtained in 25 per cent of the cases, but as there were only 4 children in this group such a finding has little significance.

Injury at birth seemed from the analysis to be a factor of more importance in the ætiology of mental deficiency. This conclusion was supported by the frequent history of a difficult birth and the high incidence of first children as well as the youth and age of the mother. Another fact which emerged from the investigation was the greater difference in the ages of the parents of mentally deficient children than in the case of the parents of a control series of mentally sound children belonging to the same social class.

REPERENCES.

(1) Report of Departmental Committee on Sterilization, London, 1934.

(2) Terman, L.M., The Measurement of Intelligence, London, 1919, 66.

(3) Dawson, Shepherd, Med. Res. Coun. Spec. Report, No. 162, 1931.

(4) Burt, C., Mental and Scholastic Tests, London, 1921, 162.

(5) Terman, L. M., Genetic Studies of Genius, 2nd Edit., 1926, Vol. I, 631.

(6) Lewis, E. D., Jour. Ment. Sc., 1933, LXXIX, 298.

(7) Findlay, L., Lancet, 1935, 1, 539.

(8) Thomson, John, Edin. Med. Jour., 1924, n.s., XXXI, 255. McNell, C.. Trans. Med. Chir. Soc., Edin., 1930-31, XLV, 175. McNell, C., Brit. Med. Jour., 1934, 1, 584. 